\title{
Antibiotic use and other risk factors at hospital level for outbreaks with Clostridium difficile PCR ribotype 027
}

\begin{abstract}
Correspondence
T. I. I. van der Kooi

tjallie.van.der.kooi@rivm.nl
\end{abstract}

Received 22 October 2007

Accepted 14 December 2007

\author{
T. I. I. van der Kooi, ${ }^{1}$ M. Koningstein, ${ }^{1}$ A. Lindemans, ${ }^{2}$ D. W. Notermans, ${ }^{1}$ \\ E. Kuijper, ${ }^{3}$ R. van den Berg, ${ }^{3}$ H. Boshuizen, ${ }^{4}$ P. M. G. Filius ${ }^{2}$ \\ and S. van den Hof $^{1}$
}
${ }^{1}$ Centre for Infectious Disease Control, RIVM Bilthoven, The Netherlands
${ }^{2}$ Dutch Working Party on Antibiotic Policy (SWAB)/Erasmus Medical Center, Rotterdam, The Netherlands
${ }^{3}$ Department of Medical Microbiology, Reference Laboratory for Clostridium difficile, Leiden University Medical Center, Leiden, The Netherlands
${ }^{4}$ Expertise Centre for Methodology and Information Services, RIVM Bilthoven, The Netherlands

\section{INTRODUCTION}

The presentation of Clostridium difficile-associated disease (CDAD) varies from mild diarrhoea to a potentially fatal pseudomembranous colitis. C. difficile takes advantage of disruption of the normal intestinal flora, as caused by antibiotic therapy, for example. Recently, C. difficile PCR ribotype 027 , toxinotype III, also known as NAP I, has been found to produce large amounts of toxins in vitro due to a deletion in a toxin-regulating gene, $t c d C$. This particular strain is associated with increased virulence and presents as a more severe disease with higher mortality and complication rates (Warny et al., 2005). Since 2003, C. difficile type

Abbreviations: CDAD, Clostridium difficile-associated disease; DDD, defined daily dose.
027 has been identified as the cause of epidemics of severe CDAD in North America (Loo et al., 2005; McDonald et al., 2005). In June 2005, this strain was discovered in several hospitals in the UK and in the Netherlands (Kuijper et al., 2005).

By the end of 2005, the bacterium had been found to cause epidemics in eight Dutch hospitals. However, in several other hospitals, type 027-associated CDAD was also found in isolated cases without further spread. The outbreaks of 027-associated CDAD have led to the formulation of national guidelines in addition to the existing guidelines for CDAD (Notermans et al., 2005). These guidelines advise on early recognition of CDAD due to type 027 and on hygiene, therapeutic and other preventive measures, such as thorough cleaning and disinfection and a 
restriction of the use of fluoroquinolones, macrolides, clindamycin and third-generation cephalosporins.

To improve prevention and control of outbreaks of type 027 , it is important to gain further insight into the association between antibiotic use and CDAD incidence at hospital level. CDAD has been associated with a wide variety of antibiotics of different classes, with clindamycin and thirdgeneration cephalosporins among the most frequently reported (Johnson \& Gerding, 2004). In the last few years, parallel to the increasing incidence of type 027, several North American studies have shown newer fluoroquinolones, such as moxifloxacin and gatifloxacin (gatifloxacin is not available in the Netherlands), to be one of the most important risk factors for CDAD (Johnson \& Gerding, 2004; Pepin et al., 2004, 2005; Muto et al., 2005; Gaynes et al., 2004; McCusker et al., 2003). These associations are only investigated at patient level and not at hospital level.

A study was designed to investigate the relationship between CDAD incidence and the preceding use of different antibiotic classes at hospital level. Comparisons were made between hospitals where type 027 caused an epidemic, hospitals where only isolated cases of type 027 were observed (without an increase in CDAD incidence) and hospitals where no outbreak of CDAD or type 027 were encountered by the end of 2005. As hygiene and other preventive measures are important factors influencing CDAD transmission (Johnson \& Gerding, 2004), the results were adjusted for these factors.

\section{METHODS}

The Netherlands has a total of 98 hospitals, of which eight have a university affiliation and 23 are top clinical teaching hospitals. Three study groups were made, based on the incidence of $C$. difficile type 027 at the end of 2005. The epidemic group consisted of all hospitals that were known to suffer or have suffered from type 027-associated CDAD outbreaks (group A, eight hospitals). Group B (six hospitals) consisted of all hospitals where type 027 was identified occasionally without an apparent increase in CDAD incidence. Additionally, 20 randomly selected hospitals without known CDAD epidemic or isolated cases of type 027 were asked to participate (group C).

To obtain information from the outbreak and the preceding period, data were collected for 2004 and 2005, on a quarterly basis. The first hospital with an outbreak due to type 027 was identified in June 2005, but in most hospitals control measures were not implemented before July 2005. Subsequently, the first six quarters are labelled 'preepidemic' and the last two quarters 'epidemic'.

Using a standardized questionnaire, data were collected on the CDAD incidence (not limited to type 027, as not all C. difficile strains were typed), the laboratory testing policy for CDAD and the infection control measures for cases of diarrhoea, CDAD and, if applicable, for cases of CDAD due to type 027 . For group A, changes in test policy and preventive measures as a consequence of the outbreak were also recorded. Based on previous surveillance, we presumed that no major changes in hygiene practices or other measures were implemented in groups B and C.

Hospital pharmacists were asked to send in data on the use of a number of antibiotic classes, generally accepted as possible risk factors for $\mathrm{CDAD}$ at patient level: fluoroquinolones, second- and third-generation cephalosporins, extended-spectrum penicillins, penicillins with $\beta$-lactamase inhibitors, carbapenems, lincomycins and macrolides. Data on antibiotic use are expressed in defined daily doses (DDD) per 10000 patient days. The CDAD incidence (new patients only) was expressed per 10000 patient days.

The collected data were described and analysed with $t$-tests for differences in mean antibiotic use (averaged over all, or several quarters) between groups and between the pre-epidemic and epidemic period. Differences in infection control were tested with chi-squared tests. If data were not normally distributed, nonparametric tests were used.

To study the association of antibiotics, hygiene practices and other preventive measures with $\mathrm{CDAD}$ incidence, quarterly observations were used. To account for the correlation of data points of individual hospitals, we used multilevel Poisson regression with an autoregressive error structure (Proc glimmix in SAS, version 9.1). Both preepidemic and epidemic quarters were included in this analysis.

Based on the results of previous studies, which showed that antibiotic use at hospital level influenced CDAD incidence after a time interval of 2-3 months (Debast et al., 2006; Gaynes et al., 2004; Biller et al., 2007; Shek et al., 2000), we modelled the CDAD incidence per quarter as a function of antibiotic use during the preceding quarter. This time-shift was not applied to data for hygiene measures or other variables.

Variables with a $P$ value of less than 0.2 in the univariate analysis were included in the multivariate analysis, using manual forward selection.

\section{RESULTS}

Not all hospitals were able to provide the requested data on a quarterly basis. For groups A, B and C respectively, the final numbers of participating hospitals were eight (100\%), five $(83 \%)$ (data on infection prevention lacking in one) and ten $(50 \%)$ (data on infection prevention lacking in one). Descriptive data for these hospitals are depicted in Table 1 . The spread of type 027 in 2005 was limited to four of the 12 provinces, mainly concentrated in the most populated central and western parts of the Netherlands. Of the ten hospitals of group C, six were located in these provinces.

\section{Incidence}

Before the first 027 outbreaks were observed and measures were taken to prevent further spread, the CDAD incidence was slightly higher in A and B hospitals than in $\mathrm{C}$ hospitals $(P=0.3$ and 0.4 , respectively). The difference between $\mathrm{A}$ and $\mathrm{C}$ hospitals became statistically significant in the epidemic period (Table 2).

\section{Antibiotic use}

Before the outbreaks occurred, the total use of the studied antibiotics was comparable between affected and unaffected hospitals (A and C). Unaffected hospitals used relatively more penicillins with $\beta$-lactamase inhibitors and fluoroquinolones, whereas outbreak hospitals had relatively higher use of extended-spectrum penicillins, third-generation cephalosporins and carbapenems. During the epidemic 
Table 1. Characteristics of hospitals included in this study

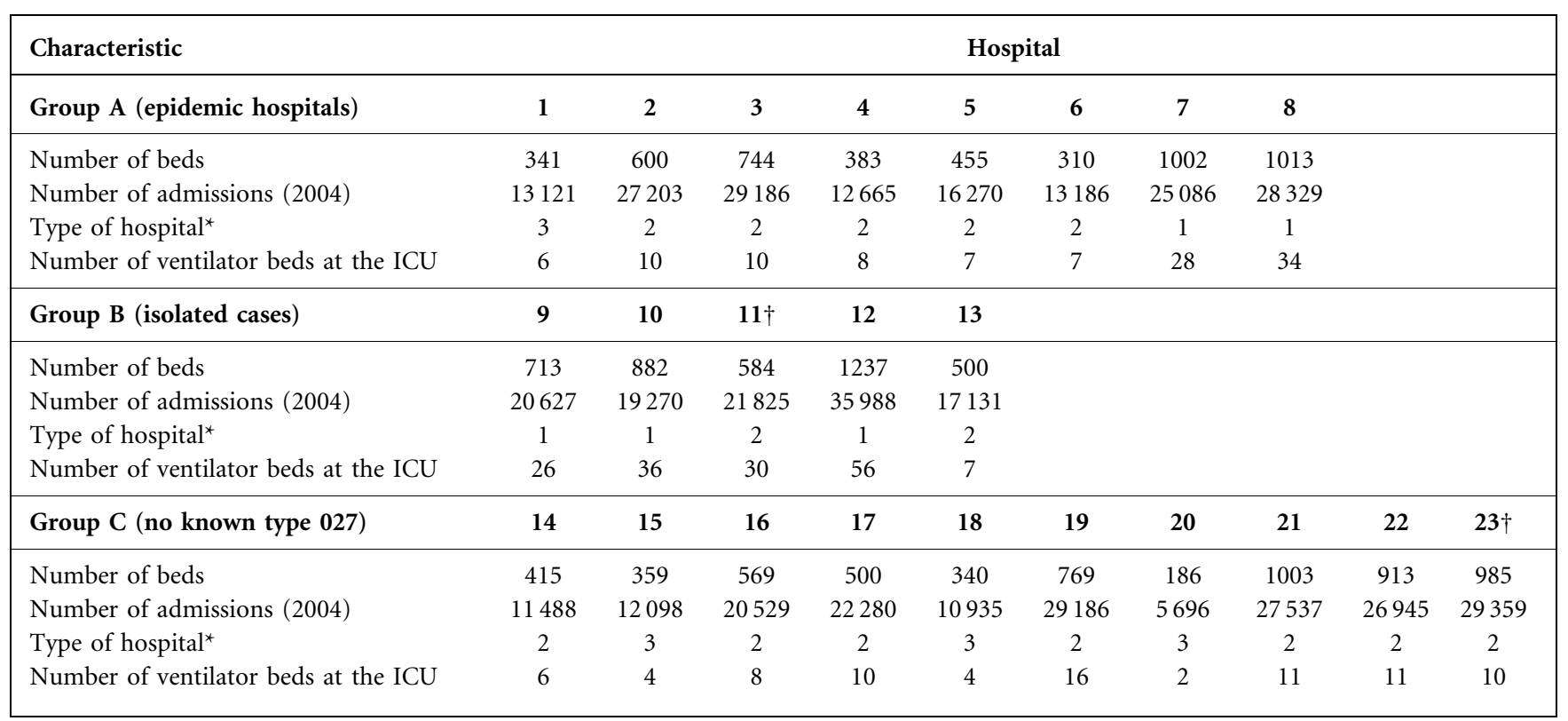

${ }^{\star}$, University hospital; 2, (other) teaching hospital; 3, non-teaching hospital.

$\dagger$ No data on infection prevention. These hospitals were not included in the regression analysis.

phase, affected hospitals used $10 \%$ less of the studied antibiotics than the unaffected hospitals $(P=0.4)$ and significantly less fluoroquinolones $(P=0.03)$. During the epidemic phase, the fluoroquinolone use in the affected hospitals decreased considerably compared with the preepidemic phase, although statistical significance was not achieved $(P=0.08)$ (Table 2$)$.

Hospitals with occasional incidences of type 027 (B) had higher total antibiotic use than the other two groups in the pre-epidemic and the outbreak period $(P=0.07$ for the preepidemic period when compared with unaffected hospitals). Extended-spectrum penicillin and second-generation cephalosporin use was significantly higher in these hospitals than in unaffected hospitals. Of the five B hospitals, three were academic hospitals. Academic hospitals had significantly higher pre-epidemic carbapenem and third-generation cephalosporin use than non-academic hospitals (data not shown). Total antibiotic use also tended to be higher in these hospitals.

\section{Pre-epidemic infection control measures}

General infection control measures for patients with diarrhoea. Infection control measures for patients with diarrhoea or CDAD differed in some aspects. Special instructions for visitors of diarrhoeal patients were provided in 4/8 A, $0 / 4 \mathrm{~B}$ and 5/9 C hospitals. The policy to dress patients in clean clothes before they left the ward was present in $4 / 6 \mathrm{~A}, 0 / 4 \mathrm{~B}$ and $3 / 9 \mathrm{C}$ hospitals, respectively. Very few hospitals disinfected the wards daily with $>250$ p.p.m. chloride (A 1/6, B 2/2 and C1/9).
In 6/8 affected A hospitals, diarrhoeal patients were nursed in wards routinely (but not exclusively), whereas this was done in 2/4 B and 5/9 unaffected hospitals. Two A hospitals indicated that they never used single rooms or cohort nursing for diarrhoeal patients. This was the case in none of the group B hospitals and in one $\mathrm{C}$ hospital.

Infection control measures for patients with CDAD. Of six A hospitals, two had special instructions for visitors of CDAD patients. This increased to $5 / 6$ during the epidemic. In $B$ and $C$ hospitals this was $1 / 4$ and $7 / 9$, respectively.

Daily disinfection with $>250$ p.p.m. chloride was performed in 3/8 A, 3/4 B and 3/9 C hospitals. In the affected hospitals this increased to $6 / 8$ during the epidemic.

Wearing gloves and gown as standard when nursing patients with CDAD happened more frequently in A hospitals (3/6) than in B (1/4) and C (2/9). Two A hospitals nursed their CDAD patients in wards (but used single rooms too) before the discovery of type 027 in the Netherlands, but stopped doing so thereafter. None of the $\mathrm{B}$ and $\mathrm{C}$ hospitals nursed CDAD patients in wards. They placed their CDAD patients in single rooms $(3 / 8$ in $A$ compared with $4 / 4$ and 7/9 in B and C, respectively) and/or used cohort nursing.

Effect of epidemic infection control measures. There was a clear decreasing trend in the CDAD incidence in the hospitals with type 027 outbreaks after the measures had been introduced $(P=0.06)$. In five hospitals there was a decrease in the second quarter of the epidemic phase compared with the quarter before (36-69\% reduction), 
Table 2. CDAD incidence and DDD of antibiotics per 10000 patient days in the pre-epidemic and epidemic periods

\begin{tabular}{|c|c|c|c|c|c|c|}
\hline \multirow[t]{2}{*}{ Parameter } & \multicolumn{3}{|c|}{ Pre-epidemic (Jan 2004-Jun 2005) } & \multicolumn{3}{|c|}{ Epidemic (Jul 2005-Dec 2005) } \\
\hline & A $(n=8)$ & B $(n=5)$ & C $(n=10)$ & A $(n=8)$ & B $(n=5)$ & C $(n=10)$ \\
\hline \multicolumn{7}{|l|}{ CDAD incidence } \\
\hline Per 10000 admissions & 19.7 & 20.4 & 13.8 & $29.1^{a_{*}}$ & 21.0 & $14.1^{a}$ \\
\hline Per 10000 patient days & 3.3 & 3.2 & 2.4 & 5.3 & 3.3 & 2.7 \\
\hline \multicolumn{7}{|l|}{ DDD per 10000 patient days } \\
\hline Total use of investigated antibiotics & 3379 & 3975 & 3540 & 3209 & 3906 & 3648 \\
\hline Fluoroquinolones & 681 & 695 & 761 & $477^{b}$ & 723 & $950^{b}$ \\
\hline Penicillins with extended spectrum & 596 & $795^{c}$ & $472^{c}$ & 658 & 781 & 559 \\
\hline Penicillins with $\beta$-lactamase inhibitors & 1046 & 1264 & 1395 & 947 & 1203 & 1308 \\
\hline Second-generation cephalosporins & 269 & $406^{d}$ & $232^{d}$ & 300 & 436 & 234 \\
\hline Third-generation cephalosporins & 236 & 250 & 196 & 283 & 234 & 192 \\
\hline Carbapenems & 61 & 130 & 26 & 65 & 131 & 28 \\
\hline Macrolides & 296 & 264 & 270 & 309 & 216 & 208 \\
\hline Lincosamides & 195 & 170 & 188 & 169 & 182 & 170 \\
\hline
\end{tabular}

${ }^{\star}$ Lower-case letters indicate values that are significantly different $(P<0.05)$.

whereas this difference was zero in two hospitals. In one hospital the number of CDAD cases was $36 \%$ higher (four CDAD cases). The limited number of affected hospitals and the short time-span after discovery of type 027, did not allow a statistical analysis of the relation between the CDAD incidence and the infection control measures.

\section{Associations with CDAD incidence}

The selected overall best fitting model for all hospitals was the autoregression model that took into account the timerelated dependency of the data per hospital.

Analysis for all hospitals. There was a significant association between the total use of the investigated antibiotics, the use of second-generation cephalosporins, extended-spectrum penicillins, macrolides and some combinations (at hospital level) with CDAD incidence in the univariate regression (Table 3). Additionally, some infection control measures were also significantly associated with the CDAD incidence. Size of the hospital (defined as less or more than 30000 patient days per quarter) and academic status were not significantly associated with CDAD incidence.

In multivariate regression, the use of second-generation cephalosporins, macrolides and total use of the studied antibiotics were significantly associated with a small increase in CDAD incidence. Nursing CDAD patients in wards, daily cleaning of the patient's room and disinfection of the bedpan disinfector room were also associated with an increase in CDAD incidence (Table 3).

Analysis for the unaffected hospitals. Table 4 depicts both the univariate and multivariate results. In multivariate analysis, the combination of second-generation cephalofosporins with macrolides was associated with CDAD incidence. This appeared to be predominantly an effect of the cephalosporins (data not shown). Among the measures associated with a higher CDAD incidence were washing hands only once (rather than twice) after caring for diarrhoea patients and nursing CDAD patients in wards. Dressing a patient with diarrhoea in clean clothes when transport was indicated and daily disinfection in case of $\mathrm{CDAD}$ were both associated with a lower CDAD incidence.

\section{DISCUSSION}

\section{Antibiotic use}

Statistically significant associations were found between the type 027-associated CDAD incidence in hospitals and the (hospital-wide) total use of the studied antibiotics, the use of second-generation cephalosporins and the use of macrolides. Interestingly, the use of second-generation cephalosporins was also significantly associated with an increased CDAD incidence in hospitals without type 027. Cefuroxim was the most frequently used second-generation cephalosporin, accounting for $90-100 \%$ in many hospitals. Hospitalwide fluoroquinolone use was not independently associated with an increased type 027-associated CDAD incidence, whereas it has been found to be a strong risk factor for type 027 at patient level in several studies, including studies in the Netherlands (Pepin et al., 2005; Loo et al., 2005; Biller et al., 2007; Debast et al., 2006; Goorhuis et al., 2007). Fluoroquinolone use in the Netherlands consists mainly of ciprofloxacin (approximately $70 \%$ in 2004) (SWAB, 2007) and this was also evident for most of the studied hospitals. This is of interest, because type 027 is resistant to ciprofloxacin (Hubert et al., 2007).

Other studies have reported considerable variation in the successes of hospitals which change their antibiotic prescrip- 
Table 3. Risk factors for CDAD in univariate $(P<0.2)$ and multivariate $(P<0.05)$ analysis for all hospitals

\begin{tabular}{|c|c|c|c|c|}
\hline \multirow[t]{2}{*}{ Risk factor } & \multicolumn{2}{|c|}{ Univariate analysis } & \multicolumn{2}{|c|}{ Multivariate analysis } \\
\hline & Relative risk & CI & Relative risk & CI \\
\hline Total use of risk-associated antibiotics & $1.02^{*} \dagger$ & $1.00-1.04$ & $1.02^{\star}$ & $1.01-1.03$ \\
\hline $\begin{array}{l}\text { Total use of risk-associated antibiotics minus } \beta \text {-lactamase-inhibiting } \\
\text { penicillins }\end{array}$ & $1.04^{*} \dagger$ & $1.01-1.06$ & - & - \\
\hline Macrolides & $1.08^{*}$ & $1.00-1.18$ & $1.10^{*}$ & $1.01-1.19$ \\
\hline Combination of second-generation cephalosporins and fluoroquinolones & $1.04^{*}$ & $1.00-1.09$ & - & - \\
\hline Combination of second-generation cephalosporins and macrolides & $1.11^{\star} \dagger$ & $1.18-1.53$ & - & - \\
\hline Combination of macrolides and fluoroquinolones & $1.04^{\star}$ & $1.00-1.09$ & - & - \\
\hline $\begin{array}{l}\text { Combination of extended-spectrum penicillins and } \beta \text {-lactamase-inhibiting } \\
\text { penicillins }\end{array}$ & $1.02^{*}$ & $1.00-1.04$ & - & - \\
\hline Daily disinfection with $>250$ p.p.m. chloride & 1.41 & $0.89-2.23$ & - & - \\
\hline Daily disinfection with chloride and cleaning of toilets three times a day & 1.48 & $0.92-2.39$ & - & - \\
\hline \multicolumn{5}{|l|}{ In case of CDAD } \\
\hline Nursing patients in wards & 1.51 & $0.90-2.53$ & 2.03 & $1.35-3.05$ \\
\hline Special instructions for visitors & 0.69 & $0.46-1.04$ & - & - \\
\hline Clean clothes for patients when transported & 0.75 & $0.48-1.16$ & - & - \\
\hline Daily cleaning & 4.25 & $0.80-22.5$ & 4.70 & $1.15-19.2$ \\
\hline Daily disinfection with $>250$ p.p.m. chloride & $1.69 \dagger$ & $1.05-2.72$ & - & - \\
\hline Daily disinfection of bedpan disinfector room with chloride & 1.52 & $1.00-2.33$ & 1.52 & $1.08-2.14$ \\
\hline
\end{tabular}

CI, $95 \%$ confidence interval.

${ }^{\star}$ Per increase of 100 DDD per 10000 bed days.

$\dagger P<0.05$ in univariate analysis.

tions in response to an increased CDAD incidence (Valiquette et al., 2007; Berild et al., 2003; Khan \& Cheesbrough, 2003; O'Connor et al., 2004; Muto et al., 2007; Veenendaal \& Kuijper, 2007). In one of the 027-affected Dutch hospitals, a ban on the use of fluoroquinolones was followed rapidly by a strong reduction in CDAD incidence (Debast et al., 2006). However, infection control measures were also changed and may have contributed to the decreased incidence. Some hospitals have managed to decrease the CDAD incidence during an epidemic with hygiene measures only, without restrictions in antibiotic use, while other hospitals succeeded by solely changing the antibiotic policy (Weil et al., 2007; Salgado et al., 2006) or observed it to be related to antibiotic policy only (Valiquette et al., 2007). It should be noted that most of the abovementioned studies are limited to only one or two hospitals.

So, although restriction of certain antibiotics at hospital level may reduce the (027-associated) CDAD incidence in an epidemic situation, the 'long-term' pre-epidemic use of these antibiotics, as analysed in our groups of hospitals, appeared to be only slightly associated with a subsequent increase in CDAD incidence. Chandler et al. (2007) studied hospital-level risk factors in Oregon during 1995-2002, a period during which the CDAD rates were increasing in $32 \%$ of the hospitals of that state and the frequency of type 027 was probably increasing. They found no association between increases in CDAD and antibiotic policy, but they did not study actual antibiotic usage.

An important restriction of our study is the fact that we only investigated antibiotic use at hospital level. Some hospital departments are more frequently affected by $C$. difficile type 027 than others. A possible association of CDAD incidence with local antibiotic use at specific departments could not be excluded. Since CDAD is associated with underlying disease, the age of patients and medication, the incidence of CDAD may vary with department (Modena et al., 2005; Kyne et al., 1998; Barbut et al., 2007; O'Connor et al., 2004). It would be interesting to know whether our findings are explained by increased use of the studied antibiotics at specific, and subsequently affected, wards only or whether increased use in other, relatively less affected, departments also leads to an increase in the incidence of resistant $C$. difficile by contributing to the general selection pressure. 
Table 4. Risk factors for CDAD in univariate $(P<0.2)$ and multivariate $(P<0.05)$ analysis for unaffected hospitals

\begin{tabular}{|c|c|c|c|c|}
\hline \multirow[t]{2}{*}{ Risk factors } & \multicolumn{2}{|c|}{ Univariate analysis } & \multicolumn{2}{|c|}{ Multivariate analysis } \\
\hline & Relative risk & CI & Relative risk & CI \\
\hline \multicolumn{5}{|l|}{ Use of antibiotics } \\
\hline Carbapenems & $1.97^{\star} \dagger$ & $1.02-3.79$ & - & - \\
\hline Macrolides & $1.14^{\star} \dagger$ & $1.03-1.26$ & - & - \\
\hline Fluoroquinolones & $0.94^{*}$ & $0.86-1.03$ & - & - \\
\hline Combination of second-generation cephalosporins and macrolides & $1.09^{*}$ & $0.99-1.20$ & 1.17 & $1.10-1.25$ \\
\hline Larger hospital size ( $>30000$ bed days per quarter) & $1.78 \dagger$ & $1.00-3.17$ & - & - \\
\hline \multicolumn{5}{|l|}{ In case of diarrhoea } \\
\hline Wearing an apron, depending on activity & 0.52 & $0.21-1.27$ & - & - \\
\hline Only washing hands once after caring for a patient & $3.46 \dagger$ & $1.17-10.3$ & 3.79 & $2.02-7.12$ \\
\hline Clean clothes for patients when transported & $0.42 \dagger$ & $0.21-0.86$ & 0.54 & $0.33-0.89$ \\
\hline \multicolumn{5}{|l|}{ In case of CDAD } \\
\hline Nursing patients in wards & $2.47 \dagger$ & $1.15-5.31$ & 1.94 & $1.17-3.22$ \\
\hline Special instructions for visitors & 0.50 & $0.19-1.35$ & - & - \\
\hline Clean clothes for patients when transported & $0.46 \dagger$ & $0.23-0.95$ & - & - \\
\hline Daily cleaning & 3.47 & $0.89-13.6$ & - & - \\
\hline Daily disinfection with $>250$ p.p.m. chloride & \multicolumn{2}{|c|}{ No model convergence } & 0.57 & $0.34-0.96$ \\
\hline
\end{tabular}

${ }^{\star}$ Per increase of 100 DDD per 10000 bed days.

$\dagger P<0.05$ in univariate analysis.

We took an interest in whether certain antibiotics would predispose to type 027 outbreaks. Considerably larger numbers of hospitals in each group would have made it possible to investigate this by employing a more straightforward approach: using the mean pre-epidemic antibiotic consumption of each hospital as the independent variable and the occurrence of an outbreak as the outcome. As CDAD incidences were highest in hospitals affected by type 027 outbreaks, we feel that this incidence-based approach gives an indication of the association of pre-epidemic antibiotic use with the occurrence of type 027 outbreaks. However, these results may have more general implications, since risk factors for the incidence of CDAD not caused by type 027 may have played a role too. For example, the use of second-generation cephalosporins is a risk factor when all hospitals are taken into account and also when analysed separately for affected and unaffected hospitals.

\section{Infection prevention policy}

Nursing CDAD patients in wards instead of in private rooms or in cohorts was associated with an increased CDAD incidence. This association was also found when hospitals without 027 were analysed separately. This confirms the results of many (often multi-faceted) interventions in individual hospitals and is consistent with relevant guidelines (Siegel et al., 2007; Zafar et al., 1998; Cherifi et al., 2006; Cartmill et al., 1994).

Counter-intuitively, daily disinfection of the bedpan cleaning area and daily cleaning of a CDAD patient's room were associated with an increased CDAD incidence when the data from all hospitals were analysed. We asked whether hospitals used disinfectant with a concentration of chloride higher than 250 p.p.m., the concentration advised for disinfection of vegetative $C$. difficile. The applied disinfectants were usually not sporicidal, as they had a concentration of chloride less than 1000 p.p.m. Recently, Fawley et al. (2007) showed that subinhibitory concentrations of chlorine-containing disinfectants and detergents can promote sporulation in $C$. difficile. Since epidemic strains, such as $C$. difficile 027 , have a higher sporulation rate than other PCR ribotypes, it could be hypothesized that daily disinfection resulted in an increase of 027 spores and their subsequent spread. Another possible explanation for this notable association is the fact that hospitals recognized initial problems and implemented some measures before the CDAD incidence increased conspicuously. This may indicate that implementing these measures alone was not sufficient to prevent increases in CDAD. Recall bias, in the timing of the measures, rather than the measures themselves, may also have played a role. A further complicating factor may have been that infection control measures were usually implemented as a 'package' that, when studied individually, may have resulted in apparently differing but 'interchangeable' results. In addition, a possible shortcoming of this kind of investigation is the difference between policy and practice. Cleaning, disinfection and other hygiene guidelines may not always be executed as advised by the department of infection control and hospital hygiene. This would lead to an underestimation of the true effects of these measures. Differences in 
compliance with regulations may exist between hospitals, and the continuation of CDAD problems probably led to greater attention and adherence to guidelines.

When only data from unaffected hospitals were analysed, such counterintuitive results were no longer statistically significant. Washing hands once (instead of twice) and nursing CDAD patients in wards were both associated with increases in incidence, whereas disinfection of the CDAD patient's room and dressing patients with diarrhoea in clean clothes before transport were associated with a decreased CDAD risk. These hospitals were not prompted by an outbreak to adapt their policy and therefore recall bias will have played a smaller role here.

In summary, we observed a significant association of the hospital-wide total use of the studied antibiotics and of second-generation cephalosporins and macrolides with CDAD incidence. However, this effect was too small to be used to predict whether some hospitals might be more prone to 027-associated outbreaks than others. More detailed investigations are necessary to clarify whether the effect of increased hospital-wide antibiotic use on CDAD incidence, observed in this study, was solely the dilution of the effects of increased antibiotic use in patients or departments that were subsequently affected by type 027 C. difficile and also to evaluate the counterintuitive results described for some hygiene measures.

\section{ACKNOWLEDGEMENTS}

We hereby recognize the important contribution of hospital pharmacists, medical microbiologists and infection control practitioners of the following hospitals in providing data for their respective institutes. Alkmaar Medical Centre, Amsterdam Academic Medical Centre, Atrium Medical Centre, Bronovo Hospital, Delfzicht Hospital, Erasmus University Medical Centre, Gelderse Vallei Hospital, Gelre Hospital, Groene Hart Hospital, Ikazia Hospital, Kennemer Gasthuis, Leiden University Medical Centre, Meander Medical Centre, Rijnstate Hospital, Rode Kruis Hospital, Slotervaart Hospital, Spaarne Hospital, St Antonius Hospital, St Jansdal Hospital, Utrecht University Medical Centre, VieCuri Medical Centre, VU University Medical Centre and Wilhelmina Hospital. There was no financial support. None of the authors declares a conflict of interest.

\section{REFERENCES}

Barbut, F., Gariazzo, B., Bonne, L., Lalande, V., Burghoffer, B., Luiuz, R. \& Petit, J. C. (2007). Clinical features of Clostridium difficileassociated infections and molecular characterization of strains: results of a retrospective study, 2000-2004. Infect Control Hosp Epidemiol 28, 131-139.

Berild, D., Smaabrekke, L., Halvorsen, D. S., Lelek, M., Stahlsberg, E. M. \& Ringertz, S. H. (2003). Clostridium difficile infections related to antibiotic use and infection control facilities in two university hospitals. J Hosp Infect 54, 202-206.

Biller, P., Shank, B., Lind, L., Brennan, M., Tkatch, L., Killgore, G., Thompson, A. \& McDonald, L. C. (2007). Moxifloxacin therapy as a risk factor for Clostridium difficile-associated disease during an outbreak: attempts to control a new epidemic strain. Infect Control Hosp Epidemiol 28, 198-201.
Cartmill, T. D., Panigrahi, H., Worsley, M. A., McCann, D. C., Nice, C. N. \& Keith, E. (1994). Management and control of a large outbreak of diarrhoea due to Clostridium difficile. J Hosp Infect 27, 1-15.

Chandler, R. E., Hedberg, K. \& Cieslak, P. R. (2007). Clostridium difficile-associated disease in Oregon: increasing incidence and hospital-level risk factors. Infect Control Hosp Epidemiol 28, 116-122.

Cherifi, S., Delmee, M., Van Broeck, J., Beyer, I., Byl, B. \& Mascart, G. (2006). Management of an outbreak of Clostridium difficile-associated disease among geriatric patients. Infect Control Hosp Epidemiol 27, 1200-1205.

Debast, S. B., Vaessen, N., Choudry, A. \& van den Berg, R. \& Kuijper E. (2006). Outbreak of Clostridium difficile PCR-ribotype 027 toxinotype III in Harderwijk, the Netherlands. In Abstracts of the 16th European Congress of Clinical Microbiology and Infectious Diseases. Nice, 1-4 April 2006. Abstract P1640. http://www.blackwellpublishing.com/eccmid16/ abstract.asp?id $=50435$

Fawley, W. N., Underwood, S., Freeman, J., Baines, S. D., Saxton, K., Stephenson, K., Owens, R. C., Jr \& Wilcox, M. H. (2007). Efficacy of hospital cleaning agents and germicides against epidemic Clostridium difficile strains. Infect Control Hosp Epidemiol 28, 920-925.

Gaynes, R., Rimland, D., Killum, E., Lowery, H. K., Johnson, T. M., II, Killgore, G. \& Tenover, F. C. (2004). Outbreak of Clostridium difficile infection in a long-term care facility: association with gatifloxacin use. Clin Infect Dis 38, 640-645.

Goorhuis, A., Van der Kooi, T., Vaessen, N., Dekker, F. W., Van den Berg, R., Harmanus, C., van den Hof, S., Notermans, D. W. \& Kuijper, E. J. (2007). Spread and epidemiology of Clostridium difficile polymerase chain reaction ribotype 027/toxinotype III in The Netherlands. Clin Infect Dis 45, 695-703.

Hubert, B., Loo, V. G., Bourgault, A. M., Poirier, L., Dascal, A., Fortin, E., Dionne, M. \& Lorange, M. (2007). A portrait of the geographic dissemination of the Clostridium difficile North American pulsed-field type 1 strain and the epidemiology of $C$. difficile-associated disease in Quebec. Clin Infect Dis 44, 238-244.

Johnson, S. \& Gerding, D. N. (2004). Clostridium difficile. In Hospital Epidemiology and Infection Control, pp. 623-634. Edited by G. M. Mayhall. Philadelphia: Lippincott Williams \& Wilkins.

Khan, R. \& Cheesbrough, J. (2003). Impact of changes in antibiotic policy on Clostridium difficile-associated diarrhoea (CDAD) over a fiveyear period in a district general hospital. J Hosp Infect 54, 104-108.

Kuijper, E. J., Debast, S. B., Van Kregten, E., Vaessen, N., Notermans, D. W. \& van den Broek, P. J. (2005). Clostridium difficile ribotype 027, toxinotype III in The Netherlands. Ned Tijdschr Geneeskd 149, 2087-2089.

Kyne, L., Merry, C., O'Connell, B., Harrington, P., Keane, C. \& O'Neill, D. (1998). Simultaneous outbreaks of two strains of toxigenic Clostridium difficile in a general hospital. J Hosp Infect 38, 101-112.

Loo, V. G., Poirier, L., Miller, M. A., Oughton, M., Libman, M. D., Michaud, S., Bourgault, A. M., Nguyen, T., Frenette, C. \& other authors (2005). A predominantly clonal multi-institutional outbreak of Clostridium difficile-associated diarrhea with high morbidity and mortality. N Engl J Med 353, 2442-2449.

McCusker, M. E., Harris, A. D., Perencevich, E. \& Roghmann, M. C. (2003). Fluoroquinolone use and Clostridium difficile-associated diarrhea. Emerg Infect Dis 9, 730-733.

McDonald, L. C., Killgore, G. E., Thompson, A., Owens, R. C., Jr, Kazakova, S. V., Sambol, S. P., Johnson, S. \& Gerding, D. N. (2005). An epidemic, toxin gene-variant strain of Clostridium difficile. $N$ Engl J Med 353, 2433-2441.

Modena, S., Bearelly, D., Swartz, K. \& Friedenberg, F. K. (2005). Clostridium difficile among hospitalized patients receiving antibiotics: a case-control study. Infect Control Hosp Epidemiol 26, 685-690. 
Muto, C. A., Pokrywka, M., Shutt, K., Mendelsohn, A. B., Nouri, K., Posey, K., Roberts, T., Croyle, K., Krystofiak, S. \& other authors (2005). A large outbreak of Clostridium difficile-associated disease with an unexpected proportion of deaths and colectomies at a teaching hospital following increased fluoroquinolone use. Infect Control Hosp Epidemiol 26, 273-280.

Muto, C. A., Blank, M. K., Marsh, J. W., Vergis, E. N., O'Leary, M. M., Shutt, K. A., Pasculle, A. W., Pokrywka, M., Garcia, J. G. \& other authors (2007). Control of an outbreak of infection with the hypervirulent Clostridium difficile B1 strain in a university hospital using a comprehensive "bundle" approach. Clin Infect Dis 45, 12661273.

Notermans, D., van Kregten, E., Speelman, P. \& Kuijper, E. (2005). Maatregelen bij een epidemische verheffing in een ziekenhuis door Clostridium difficile ribotype 027 - toxinotype III. Bilthoven, The Netherlands: Centre for Infectious Disease Control/National Institute for Public Health and the Environment (in Dutch). http:// www.rivm.nl/cib/infectieziekten/Clostridium_difficile/Clostridium_ difficile_draaiboek.jsp

O'Connor, K. A., Kingston, M., O'Donovan, M., Cryan, B., Twomey, C. \& O'Mahony, D. (2004). Antibiotic prescribing policy and Clostridium difficile diarrhoea. QJM 97, 423-429.

Pepin, J., Valiquette, L., Alary, M. E., Villemure, P., Pelletier, A., Forget, K., Pepin, K. \& Chouinard, D. (2004). Clostridium difficileassociated diarrhea in a region of Quebec from 1991 to 2003: a changing pattern of disease severity. CMAJ 171, 466-472.

Pepin, J., Saheb, N., Coulombe, M. A., Alary, M. E., Corriveau, M. P., Authier, S., Leblanc, M., Rivard, G., Bettez, M. \& other authors (2005). Emergence of fluoroquinolones as the predominant risk factor for Clostridium difficile-associated diarrhea: a cohort study during an epidemic in Quebec. Clin Infect Dis 41, 1254-1260.

Salgado, C., Fogle, P., Harley, B., Mauldin, P., Bosso, J. \& Cantey, J. (2006). Clostridium difficile associated diarrhea outbreak controlled with enhanced infection control measures. In Abstracts of the 16th Annual Scientific Meeting of the Society for Healthcare Epidemiology of America. Chicago, 18-21 March 2006. Abstract 190.

Shek, F. W., Stacey, B. S., Rendell, J., Hellier, M. D. \& Hanson, P. J. (2000). The rise of Clostridium difficile: the effect of length of stay, patient age and antibiotic use. J Hosp Infect 45, 235-237.
Siegel, J. D., Rhinehart, E., Jackson, M., Chiarello, L. \& The Healthcare Infection and Control Practices Advisory Committee (2007). Guideline for Isolation Precautions: Preventing Transmission of Infectious Agents in Healthcare Settings 2007. Atlanta, GA: Public Health Service, US Department of Health and Human Services, Centers for Disease Control and Prevention. http://www.cdc.gov/ ncidod/dhqp/pdf/Isolation2007.pdf

SWAB (2007). NETHMAP 2007 - Consumption of antimicrobial agents and antimicrobial resistance among medically important bacteria in The Netherlands. Bilthoven, The Netherlands: RIVM and Stichting Werkgroep Antibioticabeleid. http://www.swab.nl/swab/ swabcms.nsf/(WebFiles)/D552D3B6190D0461C12572FF0024F246/ \$FILE/NETHMAP_2007.pdf

Valiquette, L., Cossette, B., Garant, M. P., Diab, H. \& Pepin, J. (2007). Impact of a reduction in the use of high-risk antibiotics on the course of an epidemic of Clostridium difficile-associated disease caused by the hypervirulent NAP1/027 strain. Clin Infect Dis 45 (Suppl. 2), S112S121.

Veenendaal, D. \& Kuijper, E. (2007). Successful combat against Clostridium difficile PCR-ribotype 027 at a regional outbreak from 20032006 in the Netherlands. In Abstracts of the 17th European Congress of Clinical Microbiology and Infectious Diseases. Munich, 31 March-4 April 2007. Abstract 1732_216. http://www.blackwellpublishing.com/ eccmid17/abstract.asp?id $=56178$

Warny, M., Pepin, J., Fang, A., Killgore, G., Thompson, A., Brazier, J., Frost, E. \& McDonald, L. C. (2005). Toxin production by an emerging strain of Clostridium difficile associated with outbreaks of severe disease in North America and Europe. Lancet 366, 1079-1084.

Weil, H.-P., Mattner, F., van den Berg, R., Gastmeier, P., Kuijper, E. \& Fischer-Brügge, U. (2007). Characterisation and management of healthcare onset Clostridium difficile associated diarrhoea in a hyperendemic region in Germany. In Abstracts of the 17th European Congress of Clinical Microbiology and Infectious Diseases. Munich, 31 March-4 April 2007. Abstract 1733_1419. http://www.blackwellpublishing.com/ eccmid17/abstract.asp?id $=57718$

Zafar, A. B., Gaydos, L. A., Furlong, W. B., Nguyen, M. H. \& Mennonna, P. A. (1998). Effectiveness of infection control program in controlling nosocomial Clostridium difficile. Am J Infect Control 26, 588-593. 